\title{
Kiat Menjadi Pegiat dan Pengajar Bahasa Indonesia bagi Penutur Asing: Membidik Potensi dan Peluang
}

\author{
Bejo Sutrisno $^{1}$, Agus Sulaeman ${ }^{2}$, Mukhlasul Fasikh ${ }^{1}$, Audi Yundayani ${ }^{3 *}$ \\ ${ }^{1}$ Sastra Inggris, STIBA IEC \\ ${ }^{2}$ Pendidikan Bahasa Indonesia, Universitas Muhammadiyah Tangerang \\ ${ }^{3}$ Pendidikan Bahasa Inggris, STKIP Kusuma Negara \\ *audi_yundayani@stkipkusumanegara.ac.id
}

\begin{abstract}
Abstrak
Internasionalisasi bahasa Indonesia memberikan dampak positif terhadap munculnya peluang menjadi pegiat dan pengajar bahasa Indonesia bagi Penutur Asing (BIPA). Peluang dan potensi ini menjadi sebuah daya tarik tersendiri, hanya saja masih terdapat tanda tanya besar terkait apa itu BIPA, apa yang harus disiapkan, dan apa yang harus dilakukan untuk mengambil peluang tersebut. Kegiatan ini ditujukan untuk memberikan informasi tentang BIPA, memberikan gambaran tentang peluangpeluang apa saja yang muncul, bagaimana menjadi pegiat dan pengajar BIPA, dan berbagai tantangan yang akan dihadapi. Kegiatan yang diikuti oleh 98 peserta dari berbagai kalangan dilaksanakan dalam bentuk seminar dalam jaringan (daring) dengan pemaparan makalah dan pengalaman dari pemateri diikuti dengan sesi diskusi. Hasil dari kegiatan ini memberikan dampak positif. Peserta terlibat secara aktif dalam sesi diskusi. Umpan balik yang diberikan peserta setelah selesai acara menggambarkan mereka termotivasi untuk ingin lebih tahu lagi tentang BIPA. Mereka juga berharap STIBA IEC dapat melakukan lokakarya BIPA dasar untuk program kegiatan selanjutnya. Informasi tentang BIPA yang diberikan dapat memberikan stimulus dan informasi yang tepat bagi masyarakat luas.
\end{abstract}

Kata kunci: Bahasa Indonesia bagi Penutur Asing (BIPA), seminar dalam jaringan.

Dikirim: 7 Oktober 2021

Direvisi: 14 Oktober 2021

Diterima: 15 oktober 2021

\section{PENDAHULUAN}

Bahasa Indonesia bagi Penutur Asing, untuk selanjutnya disebut BIPA, merupakan program pembelajaran keterampilan berbahasa Indonesia bagi penutur asing (Susilo, 2016; Alawiyah, 2014; Wahyono \& Farahsani, 2017), baik dalam keterampilan menyimak, berbicara, membaca, maupun menulis (Widianto, 2017). Pengajaran BIPA merupakan hal yang krusial karena merupakan salah satu langkah nyata penting dalam meningkatkan kiprah eksistensi bahasa Indonesia di dunia internasional. Internasionalisasi bahasa Indonesia dapat ditingkatkan melalui pengajaran BIPA yang harus didukung oleh semua lembaga yang memiliki relevansi (Gloriani, 2017; Ningrum, Waluyo \& Winarni, 2017). Hal inilah yang menggambarkan perlunya komitmen semua pihak dalam rangka menghantarkan Bahasa Indonesia menjadi Bahasa Internasional (Masreng, 2015; Werdiningsih, 2018; Anto, Hilaliyah \& Akbar, 2019). Pengajaran BIPA juga tidak hanya dilakukan di dalam negeri, tetapi juga di luar Indonesia (Tanwin, 2020). Hal tersebut pada akhirnya membawa dampak baik, salah satunya adalah bertambahnya jumlah penutur dan area penggunaan bahasa Indonesia.

Pengetahuan pelajar BIPA secara garis besar dapat dikategorikan sebagai seorang anak kecil yang belum mengetahui bagaimana penggunaan bahasa 
berdasarkan konteks lingkungannya. Sebagian besar pelajar BIPA masih belum mengenal pengetahuan bahasa Indonesia dengan baik dan benar (Sari, 2020). Mereka dapat diumpamakan sebagai sosok bayi yang baru lahir dan perlu didewasakan (Ulumuddin \& Wismanto, 2014), sehingga dibutuhkan proses pendewasaan yang harus dilakukan secara profesional diiringi dengan tanggung jawab keilmuan dengan melibatkan berbagai pihak.

Peluang untuk menjadi pegiat dan pengajar BIPA sangat terbuka luas. Berbagai latar belakang pendidikan memiliki peluang yang sama, meski penguasaan bahasa asing dapat membantu proses pengajaran, tetapi hal tersebut tidak mutlak. Mengajar BIPA bukan hanya tentang pengajar mahir berbahasa asing, tetapi mereka harus menguasai ilmu pedagogi yang berfokus pada ilmu pembelajaran bahasa Indonesia. Hal lain yang harus diingat adalah pengajar BIPA merupakan duta bangsa (Sukma dkk., 2021), sehingga penguasaan tentang budaya, termasuk nilai-nilai, adat, dan kebiasaan bangsa Indonesia juga harus dikuasai dengan benar. Mereka juga dituntut untuk tahu bagaimana mengintegrasikan budaya dalam pengajaran BIPA (Rohimah, 2018; Arwansyah \& Widodo, 2017). Pada akhirnya penguasaan terhadap hal-hal tersebut merupakan modal dasar yang akan memudahkan langkah untuk menjadi pegiat dan pengajar BIPA.

Fenomena yang terjadi di masyarakat adalah sebagian dari mereka belum memahami tentang BIPA. Ada yang memahami bahwa BIPA adalah tentang belajar bahasa Indonesia bagi siapa saja termasuk bagi orang Indonesia. Sebagian lagi berpendapat bahwa pengajar BIPA harus menguasai bahasa Inggris sebagai bahasa pengantar, atau pengajar BIPA hanya dibatasi oleh orang yang memiliki latar belakang pendidikan bahasa Indonesia. Berbagai pemahaman tersebut sebaiknya diluruskan sehingga pada akhirnya mereka mengerti apa itu BIPA, bagaimana menjadi pegiat dan pengajar BIPA, apa yang harus disiapkan, dan peluang serta potensi apa saja yang terbuka atau yang akan didapat sebagai pegiat dan pengajar BIPA.

Upaya untuk membantu memberi gambaran terkait dengan BIPA menjadi hal yang penting untuk dilakukan sebagai bentuk kontribusi terhadap internasionalisasi Bahasa Indonesia. Sekolah Tinggi Bahasa Asing (STIBA) IEC, Jakarta sebagai institusi pendidikan merasa terpanggil untuk memberikan edukasi sehingga dengan menggandeng Asosiasi Pegiat dan Pengajar Bahasa Indonesia bagi Penutur Asing (APPBIPA) cabang Banten, bersama-sama dengan Universitas Muhammadiyah Tangerang, dan STKIP Kusuma Negara menyelenggarakan seminar daring bertema, Kiat Menjadi Pegiat dan Pengajar Bahasa Indonesia bagi Penutur Asing: Membidik Potensi dan Peluang.

\section{METODE PELAKSANAAN}

Kegiatan seminar daring dilaksanakan pada hari Rabu, tanggal 21 April 2021, pukul 13.00 sampai dengan pukul 14.30 WIB. Narasumber utama adalah Bapak Dr. Agus Sulaeman, M.Pd. dari Universitas Muhammadiyah Tangerang yang sekaligus menjabat sebagai ketua APPBIPA cabang Banten. Acara dipandu oleh moderator, Ibu Dr. Audi Yundayani, M.Pd., dari STKIP Kusuma Negara. Acara dibuka oleh Bapak Dr. Bejo Sutrisno, M.Pd., selaku pimpinan STIBA IEC, Jakarta. Keberlangsungan acara di bawah koordinasi Bapak Mukhlasul Fasikh, M.Pd., dari STIBA IEC, Jakarta. 
Peserta seminar tercatat sejumlah 98 orang yang berasal dari berbagai kalangan dan lokasi di Indonesia. Acara dilaksanakan dengan metode ceramah dalam penyampaian materi dan dilanjutkan dengan diskusi. Untuk menyebarluaskan kegiatan seminar, maka disediakan video rekaman acara yang diunggah ke YouTube pada link https://www.youtube.com/watch?v=UD1CmsxSMLg dan https://www.youtube.com/watch?v=AdEhgGDQuK0.

\section{HASIL DAN PEMBAHASAN}

Kegiatan ini diawali dengan pembukaan oleh Bapak Mukhlasul Fasikh, M.Pd., sebagai pewara tepat pada pukul 13.00 WIB, kemudian dilanjutkan dengan sambutan pembuka dari tuan rumah yang disampaikan oleh Bapak Dr. Bejo Sutrisno, M.Pd. sebagai Pimpinan STIBA IEC Jakarta. Beliau menyampaikan ucapan terima kasih dan memastikan komitmen STIBA IEC untuk mengambil peran dalam penyebaran pengetahuan melalui program pengabdian masyarakat yang berkelanjutan.

Acara kemudian diserahkan pewara ke moderator, Ibu Dr. Audi Yundayani, M.Pd., untuk dilanjutkan. Moderator mengawali sesi pemateri dengan menyapa narasumber, Bapak Dr. Agus Sulaeman, M.Pd., dan mempersilahkan beliau untuk menyampaikan paparan materi selama lebih kurang 50 menit. Pemateri menyampaikan di awal tentang berbagai definisi mendasar tentang BIPA. Program BIPA adalah program pembelajaran bahasa Indonesia untuk orang-orang yang bahasa ibunya bukan bahasa Indonesia dan bisa saja yang berasal dari luar Indonesia. Lebih lanjut lagi disampaikan bahwa Pemerintah Indonesia melalui Pusat Pengembangan Strategi dan Diplomasi Kebahasaan (PPSDK) Kemendikbud membuat program terkait dengan BIPA yang diatur dalam peraturan pemerintah (PP) nomor 24, tahun 2019. Program untuk mengiternasionalisasikan bahasa Indonesia membuka peluang untuk menjadi pegiat dan pengajar BIPA.

Untuk menjadi pengajar BIPA bisa dimulai dengan mengikuti berbagai pelatihan yang biasanya diselenggarakan secara terprogram, berkelanjutan, dan berdasarkan tingkatan penguasaan. Pemerintah juga melakukan seleksi pengajar BIPA di setiap tahunnya untuk dikirim ke berbagai negara di belahan dunia. Ada persyaratan khusus yang harus dipenuhi untuk layak dikirim.

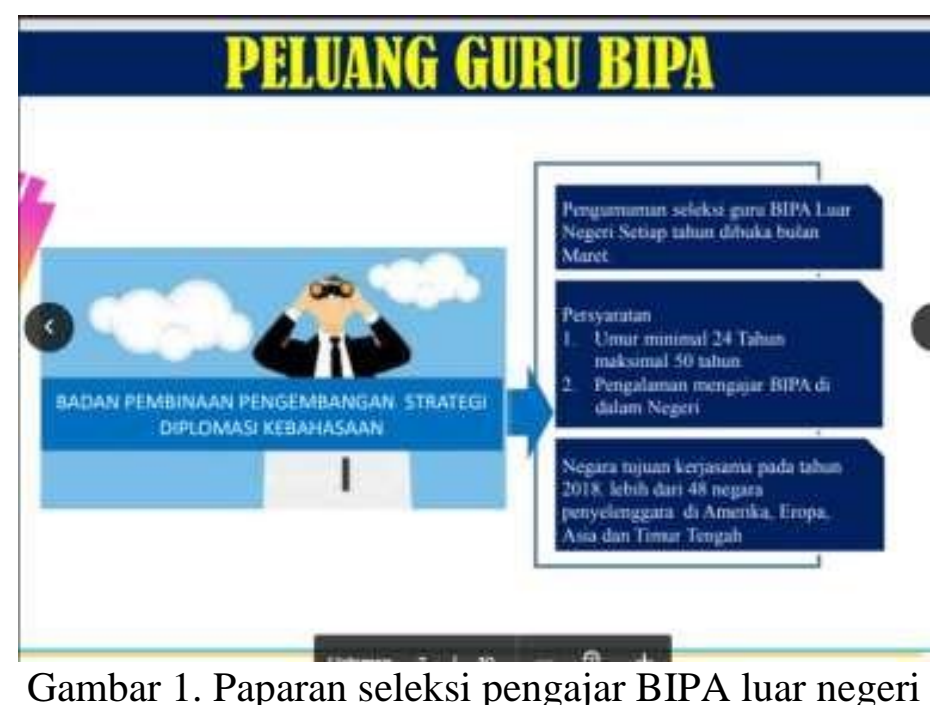

Gambar 1. Paparan seleksi pengajar BIPA luar negeri 
Pemateri juga menyampaikan bahwa saat ini telah banyak bermunculan pengajar BIPA mandiri yang menggunakan sosial media sebagai sarana promosi. Biasanya mereka akan mendapatkan klien dan melakukan kerja sama secara langsung. Pemateri menyarankan agar para pengajar BIPA mandiri dapat bergabung dalam lembaga APPBIPA. Mereka juga dapat berafiliasi dengan institusi pendidikan professional sebagai pengajar BIPA paruh waktu.

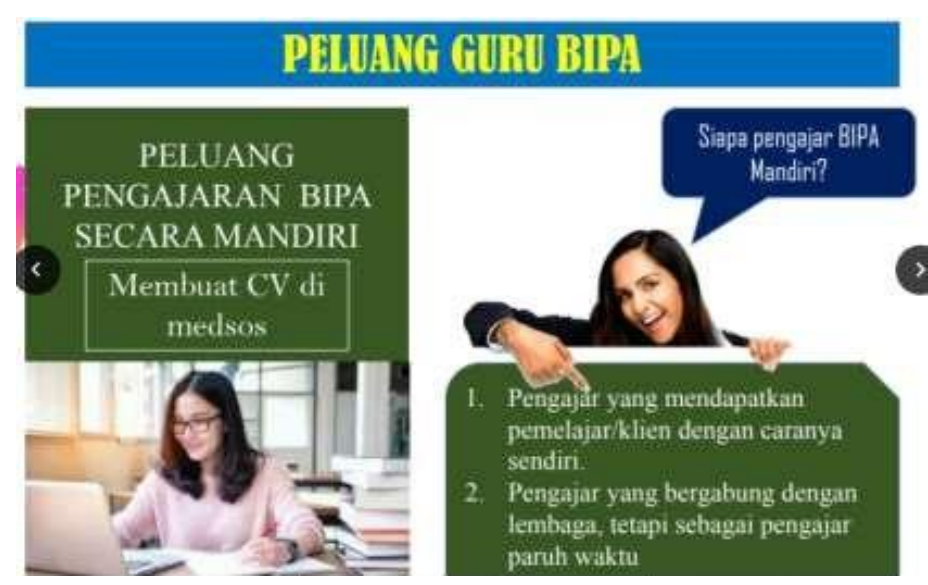

Gambar 2. Paparan seleksi pengajar BIPA mandiri

Pemateri juga menyampaikan bahwa pengajar BIPA dapat mengajar setidaknya di empat lokasi yaitu, keduataan, perusahaan, lembaga-lembaga kursus, dan juga bisa secara private langsung ke rumah-rumah.

\section{MENGAJAR DI MANA SAJA?}

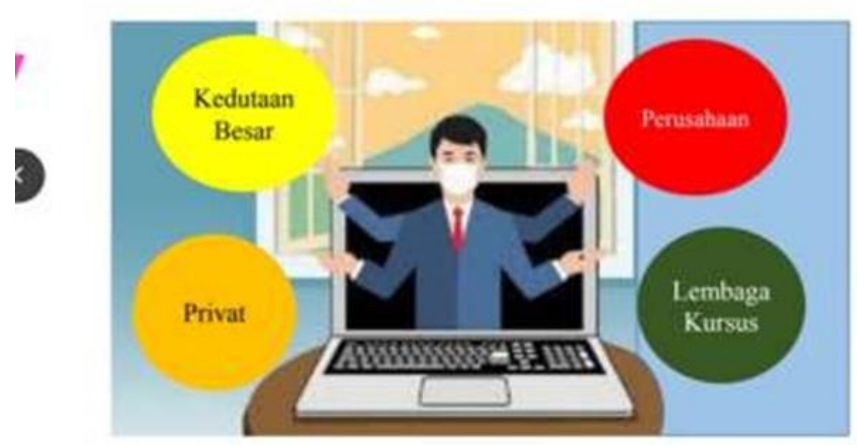

Gambar 3. Paparan potensi pengajar BIPA

Pemateri juga menguatkan bahwa pelajar BIPA bisa datang dari berbagai kalangan seperti, karyawan, pimpinan perusahaan, diplomat, akademisi, mahasiswa asing, guru di sekolah internasional, ibu rumah tangga, pemandu wisata, relawan, dan sebagainya. 


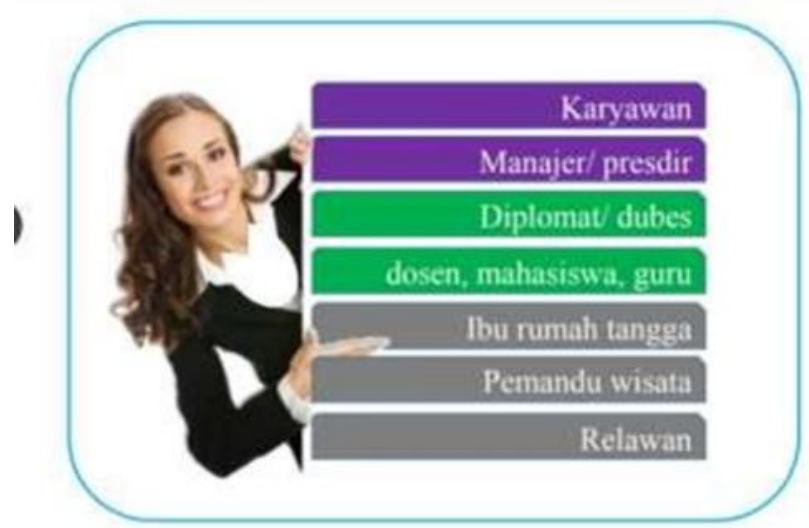

Gambar 4. Paparan latar belakang pelajar BIPA

Di akhir pemaparan, pemateri menyampaikan berbagai tantangan yang dihadapi oleh pengajar BIPA. Disampaikan bahwa tantangan akan menguatkan dan memberikan pengalaman yang tak tergantikan.

\section{TANTANGAN}

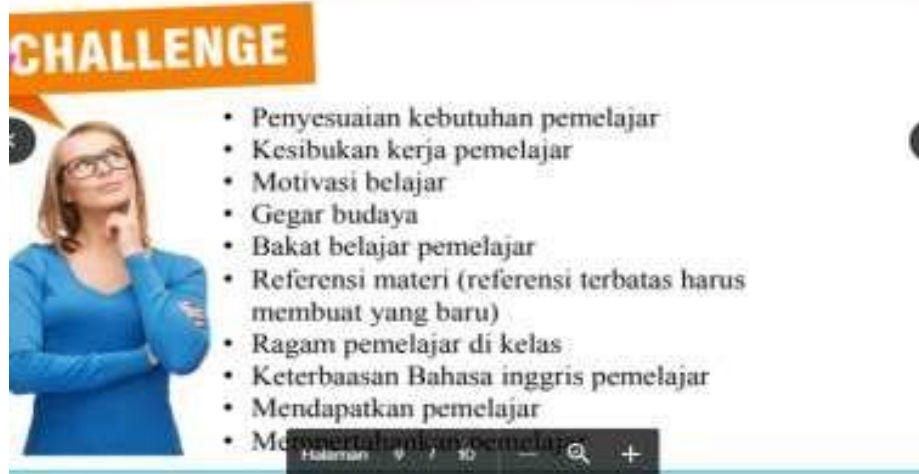

Gambar 5. Paparan tantangan pengajar BIPA

Setelah pemaparan selesai disampaikan, moderator membuka sesi diskusi. Beberapa pertanyaan yang sempat terjawab adalah sebagai berikut,

1. Apa manfaat dari BIPA? Negara mana saja yang sudah menyelenggarakan BIPA? Bagaimana pengajaran tersebut berlangsung?

2. Apa langkah-langkah yang bisa ditempuh dari sekarang untuk bisa menjadi pengajar dan pegiat BIPA?

3. Bagaimana persyaratan untuk menjadi seorang pengajar BIPA?

4. Karena bahasa Inggris dan bahasa Indonesia merupakan dua bahasa yang berbeda maka bagaimana cara lulusan sastra Inggris mengajar BIPA? Meskipun yang diajarkannya adalah orang asing namun latar belakang pendidikan lulusan sastra Inggris bukan di bahasa Indonesia.

5. Kenapa narasumber memilih mengajar dan pegiat BIPA?

6. Bagaimana cara belajar BIPA dalam bahasa Inggris agar kita mengerti dengan cepat terutama di keterampilan menyimak? 
7. Apakah BIPA hanya terfokus pada sistem pengajaran?

8. Apa langkah awal mengenalkan bahasa Indonesia terhadap orang asing? Apakah dimulai kosa kata terlebih dahulu atau langsung mengikat kata menjadi kalimat?

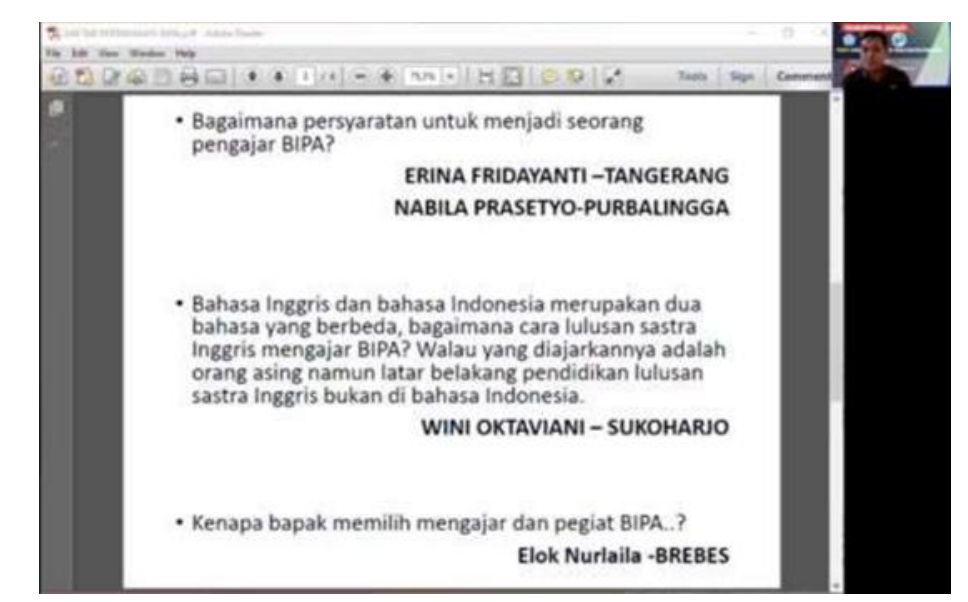

Gambar 6. Cuplikan pertanyaan yang disampaikan peserta

Melihat banyak pertanyaan yang disampaikan, maka dapat disimpulkan bahwa materi yang dibawakan cukup menarik karena sesuai dengan apa yang dibutuhkan oleh peserta. Acara kemudian di akhiri oleh pemateri dan moderator, kemudian ditutup oleh pewara.

\section{SIMPULAN}

Program pembelajaran keterampilan berbahasa Indonesia bagi penutur asing mulai menjadi sebuah kebutuhan sebagai bagian dari internasionalisasi bahasa Indonesia. Potensi ini memberikan peluang yang cukup menggiurkan bagi pada pegiat dan pengajar BIPA sehingga peningkatan kompetensi harus terus dilakukan sebagai sebuah tuntutan. Kegiatan pengabdian kepada masyarakat yang diselenggarakan secara kolaborasi antar institusi perguruan tinggi mendapatkan apresiasi yang sangat baik. Peserta terlihat antusias untuk terlibat aktif selama acara, bahkan beberapa peserta berharap agar kegiatan seperti ini dilakukan secara berkelanjutan.

\section{UCAPAN TERIMA KASIH}

Apresiasi diucapkan kepada pimpinan STIBA IEC, Jakarta, pimpinan Universitas Muhammadiyah, Tangerang, dan pimpinan STKIP Kusuma Negara, Jakarta, yang telah berkenan untuk mendukung kolaborasi kegiatan pengabdian masyarakat ini. Penghargaan juga disampaikan kepada jajaran pengurus APPBIPA atas dukungannya.

\section{DAFTAR PUSTAKA}

Alawiyah, W. S. (2014). Pengembangan Tes Keterampilan Menulis Sebagai Upaya Penyiapan Alat Uji Kemahiran Berbahasa Indonesia Bagi Penutur Asing. Bahtera Bahasa: Antologi Pendidikan Bahasa dan Sastra 
Indonesia, 1(6), 1-10.

Anggaira, A. S. (2019). Literasi Terkini Dalam Pembelajaran BIPA Pada Era Revolusi Digital. In Prosiding Seminar Nasional Program Pascasarjana Universitas PGRI Palembang, 12(1), 29-39.

Anto, P., Hilaliyah, H., \& Akbar, T. (2019). Pengutamaan Bahasa Indonesia: Suatu Langkah Aplikatif. El Banar: Jurnal Pendidikan dan Pengajaran, 2(1), 17-24.

Arwansyah, Y. B., Suwandi, S., \& Widodo, S. T. (2017). Revitalisasi peran budaya lokal dalam materi pembelajaran bahasa Indonesia bagi penutur asing (BIPA). Proceedings Education and Language International Conference, pp. 915-920.

Gloriani, Y. (2017). Konservasi dan Revitalisasi Bahasa sebagai Salah Satu Upaya Internasionalisasi Bahasa Indonesia. Fon: Jurnal Pendidikan Bahasa dan Sastra Indonesia, 11(2), 1-11.

Masreng, R. (2015). Diplomasi bahasa menjembatani keragaman bahasa daerah dan pengutamaan bahasa Indonesia. Retorika: Jurnal Ilmu Bahasa, 1(1), 155-167.

Ningrum, R. K., Waluyo, H. J., \& Winarni, R. (2017). BIPA (Bahasa Indonesia Penutur Asing) sebagai upaya internasionalisasi universitas di Indonesia. The 1st Education and Language International Conference Proceeding, pp.726732.

Rohimah, D. F. (2018). Internasionalisasi bahasa Indonesia dan internalisasi budaya Indonesia melalui bahasa Indonesia bagi penutur asing (BIPA). An-Nas: Jurnal Humaniora, 2(2), 199-212.

Sari, R. (2020). Belajar Bahasa Indonesia bagi Penutur Asing (BIPA) dengan Mudah dan Cepat untuk Pemula: Komunikasi Aktif. Penerbit Pustaka Rumah Cinta.

Sukma, B. P., Puspitasari, D. A., Amalia, C., Okitasari, I., Prayoga, R. A., Amanat, T., ... \& Mifthah, M. Y. F. (2021). Demi Bahasa Bermanfaat Dan Bermartabat: Percikan Pemikiran Strategi Kebahasaan Dalam Dinamika Bahasa, Pendidikan, Dan Kebudayaan Era Kiwari. Deepublish.

Susilo, J. (2016). Pengembangan kurikulum bahasa Indonesia bagi penutur asing. Deiksis Jurnal Pendidikan Bahasa dan Sastra Indonesia, 3(1), 44-53.

Tanwin, S. (2020). Pembelajaran BIPA (Bahasa Indonesia Penutur Asing) Dalam Upaya Internasionalisasi Universitas di Indonesia pada Era Globalisasi. Bahasa Indonesia Prima (BIP), 2(2), 31-38.

Ulumuddin, A., \& Wismanto, A. (2014). Bahan ajar bahasa Indonesia ranah sosial budaya bagiapenutur bahasa asing (BIPA). Jurnal Sasindo, 2(1), 15-35.

Wahyono, T., \& Farahsani, Y. (2017). Penerapan pendekatan proses untuk meningkatkan keterampilan berbicara bahasa indonesia bagi penutur asing. AKSIS: Jurnal Pendidikan Bahasa dan Sastra Indonesia, 1(2), 204-220.

Werdiningsih, E. (2018). Menumbuhkan Rasa Bangga Generasi Muda Terhadap Bahasa Indonesia sebagai Bahasa Nasional dan Internasional. Likhitaprajna, 18(2), 20-25.

Widianto, E. (2017). Media Wayang Mini dalam Pembelajaran Keterampilan Berbicara Bagi Pemelajar BIPA A1 Universitas Ezzitouna Tunisia. Kredo: Jurnal Ilmiah Bahasa dan Sastra, 1(1), 120-143. 